\title{
LC-MS/MS based determination of basal- and ACTH-stimulated plasma concentrations of 11 steroid hormones: implications for detecting heterozygote CYP21A2 mutation carriers
}

\author{
A E Kulle' ${ }^{1}$, F G Riepe ${ }^{1}$, J Hedderich ${ }^{2}$, W G Sippell ${ }^{1}$, J Schmitz ${ }^{1}$, L Niermeyer ${ }^{1}$ \\ and $\mathbf{P}$ M Holterhus ${ }^{1}$ \\ ${ }^{1}$ Division of Pediatric Endocrinology and Diabetes, Department of Pediatrics and ${ }^{2}$ Institute of Medical Informatics \\ and Statistics, University Hospital Schleswig-Holstein, Christian-Albrechts University Kiel, Schwanenweg 20, \\ D-24105 Kiel, Germany
}

Correspondence should be addressed to A E Kulle

Email

alexandra.kulle@uksh.de

\begin{abstract}
Objective: Heterozygosity in 21-hydroxylase deficiency (21OHD) has been associated with hyperandrogenemic symptoms in children and adults. Moreover, the carrier status is mandatory for genetic counseling. We aimed at defining a hormonal parameter for carrier detection by mass spectrometry.

Design: Eleven basal and ACTH-stimulated steroid hormones of heterozygous carriers of CYP21A2 mutations and control individuals were compared.

Method: Hormones were determined in plasma samples by liquid chromatography tandem mass spectrometry (LC-MS/MS) in 58 carriers ( 35 males, 23 females, age range $6-78$ years) and 44 random controls ( 25 males, 19 females, age range 8-58 years). Results: Heterozygotes could be identified best applying the 17-hydroxyprogesterone +21 -deoxycortisol/cortisol $\times 1000$ $((170 H P+215) / F \times 1000)$ equation 30 min after ACTH injection. An optimal cut-off value of 8.4 provided $89 \%$ sensitivity and specificity. Considering this data and a published frequency of heterozygotes of $1 / 50$ to $1 / 61$, the positive predictive value (PPV) of this cut-off is $12 \%$. Of note, the negative predictive value (NPV) excluding heterozygosity in a given patient is $99.8 \%$. Conclusion: Considering only marginal biochemical effects anticipated from heterozygosity, the stimulated ((17OHP $+21 \mathrm{~S}) /$ $\mathrm{F} \times 1000$ ) identifies and excludes heterozygotes remarkably well. Nevertheless, LC-MS/MS cannot replace genetic testing, since sensitivity and specificity did not reach $100 \%$. However, due to the considerably high NPV of the optimal cut-off and to a specificity of even $100 \%$ applying a cut-off higher than 14.7 , hormonal assessment of heterozygosity can be of significant aid in conditions with limited access to genetic testing, as in some health care systems. The $((170 \mathrm{HP}+21 \mathrm{~S}) / \mathrm{F} \times 1000)$ equation can guide diagnostic considerations in the differential diagnosis of hyperandrogenism.
\end{abstract}

\section{Introduction}

21-hydroxylase deficiency (21OHD) is the most common form of congenital adrenal hyperplasia $(\mathrm{CAH})(1,2,3)$. Classic 21OHD has an incidence of about 1:10 000-1:15 $000(4,5,6)$. Prevalence rates for non-classic 21OHD are much higher. Little data on heterozygote rates has been published. Based on (c) 2015 European Society of Endocrinology Printed in Great Britain the data published by Pang \& Clark (6), a frequency of heterozygous carriers in Europe could be calculated using the Hardy-Weinberg principle, resulting in a 1:50 to 1:61 ratio.

CYP21A2 mutations may contribute to clinically evident hyperandrogenemia $(7,8)$. A high prevalence of 
heterozygosity of CYP21A2 gene mutations has been documented in premature pubarche $(9,10)$. Therefore, heterozygosity of CYP21A2 gene mutations has to be considered in the differential diagnosis of hyperandrogenemic symptoms. The carrier status is also mandatory for counseling parents who are themselves affected by CAH and in families where one parent has proven carrier status. At the hormone level, heterozygotes have normal or only slightly elevated basal plasma levels of 17-hydroxyprogesterone (17OHP) (3). Following corticotrophin (ACTH) injection, heterozygotes usually show an increased rise of $17 \mathrm{OHP}$ compared with controls, but it is not possible to identify heterozygosity based on stimulated $17 \mathrm{OHP}$ alone $(11,12$, $13,14)$. A different approach to detect heterozygotes is the calculation of substrate-to-product ratios. In an earlier study, in the pre-liquid chromatography tandem mass spectrometry (pre-LC-MS/MS) era, 17OHP/deoxycorticosterone (DOC)-ratios following corticotrophin stimulation had led to the identification of $100 \%$ of the carriers investigated (15). Since the determination of steroid hormones is now largely performed by mass spectrometry, the aim of the present study is to analyze 11 steroid hormones measured by LC-MS/MS in controls and in proven heterozygous carriers of CYP21A2 mutations, in order to define hormonal cut-off values for carrier identification.

\section{Subjects and methods}

\section{Volunteers}

The study was approved by the Ethics Committee of the Christian-Albrechts-University, Kiel, Germany. Subjects provided written informed consent. One cohort of study volunteers, aged 6-78 years, comprised relatives of index patients with proven 210HD $(n=58 ; 35$ males and 23 females). The second independent cohort consisted of healthy volunteers ( $n=44 ; 25$ males and 19 females), aged $8-56$ years. Exclusion criteria included any known chronic illness, pregnancy (ruled out by determining $\beta$ human chorionic gonadotrophin ( $\beta$-hCG)) and recent use of glucocorticoids.

\section{ACTH test}

ACTH stimulation was performed between 0800 and $1000 \mathrm{~h}$ on a weekend morning. All women were tested in the early follicular phase. No subjects were in menopause. Blood samples were obtained by venipuncture before, 30 and $60 \mathrm{~min}$ after application of $250 \mu \mathrm{g}$ of synacthen (Novartis Pharma) i.v.

\section{Molecular analysis of the CYP21A2 locus}

First we employed multiplex minisequencing to detect the most common CYP21A2 mutations (16) using an automated ABI 310 Sequencer (Applied Biosystems, Inc.). This was followed by sequencing the whole coding CYP21A2 region and all intron exon boundaries (17). In addition, MLPA-multiplex ligation-dependent probe amplification (SALSA MLPA kit CAH, MCR-Holland, Amsterdam, The Netherlands) was performed to identify large gene deletions.

\section{Hormone analysis}

Plasma concentrations of 11 steroid hormones, comprising mineralocorticoids, glucocorticoids and androgens, were determined using UPLC Quattro Premier/Xe system (Waters, Milford, MA, USA) as previously described $(18,19)$. In brief, aliquots of plasma samples, calibrator and controls with a volume of $0.1 \mathrm{ml}$ were combined with the internal standard mixture to monitor recovery. All samples were extracted using Oasis MAX SPE system Plates (Waters). To separate all isobaric substances, a UPLC method was used with a Waters UPLC BEH C18 column $(1.7 \mu \mathrm{m}$, $100 \times 2.1$ ) at a flow rate of $0.4 \mathrm{ml} / \mathrm{min}$ at $50{ }^{\circ} \mathrm{C}$. Water (A) and acetonitrile (B) both with $0.01 \%$ formic acid were used. A gradient was used: from 29\% to 91\% acetonitrile in 2 min, a step gradient to $100 \%$ acetonitrile and re-equilibration to initial conditions in $2.5 \mathrm{~min}$. Total running time was $5 \mathrm{~min}$ and the injection volume was $20 \mu \mathrm{l}$. Electrospray was used and for each hormone two multiple reaction monitoring (MRM) transitions were recorded. The retention time for the isobaric molecules 21-deoxycortisol (21S), corticosterone and 11-deoxycortisol (11S) were 3.49, 3.61 and $3.94 \mathrm{~min}$. The quantifier and qualifier transitions (m/e) for these hormones were: $11 \mathrm{~S} 347>97,347>109 ; 21 S$ 347>311, $347>121$; corticosterone 347>121, 347>311 (Supplementary Figures 1 and 2, see section on supplementary data given at the end of this article). $21 \mathrm{~S}$ and corticosterone are not completely baseline-separated, but the calculated resolution ( $R=1.85$ ) supports suitability of the detection method for valid quantification of these two steroids. The limit of quantification was for $17 \mathrm{OHP} 0.03 \mathrm{ng} / \mathrm{ml}$, for $21 \mathrm{~S}$ $0.04 \mathrm{ng} / \mathrm{ml}$ and for cortisol $0.8 \mathrm{ng} / \mathrm{ml}$. The method used is specific to the hormones of interest $(18,19)$.

\section{Statistical analysis}

Statistical evaluation was performed using SigmaStat (Systat Software, Erkrath, Germany) and SPSS (SPSS statistics for Windows V20, IBM Corp., Armonk, NY, USA). 


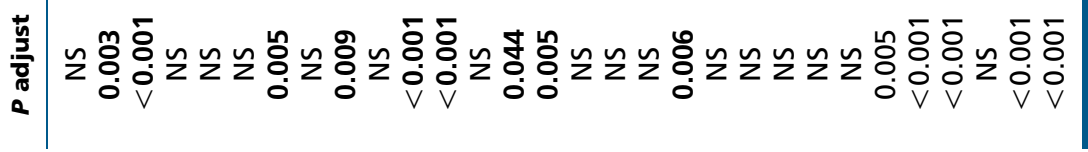

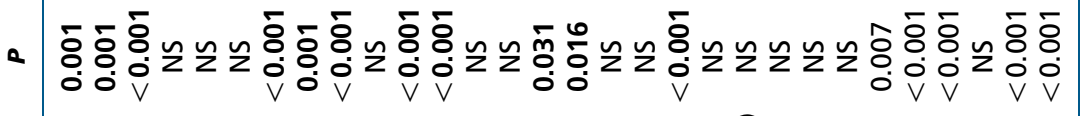

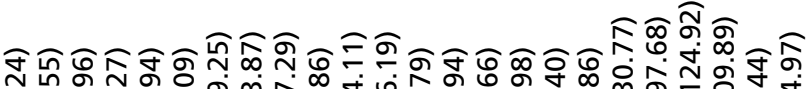

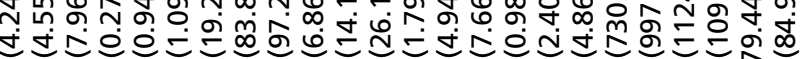
胡 m m

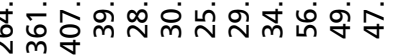

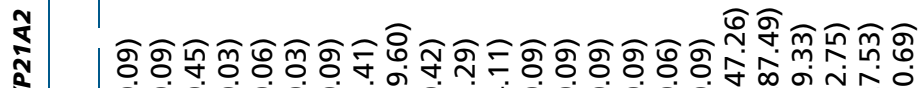

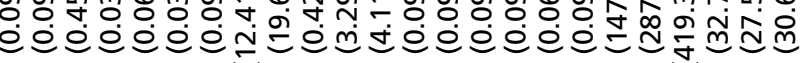

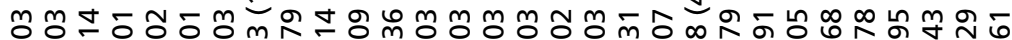

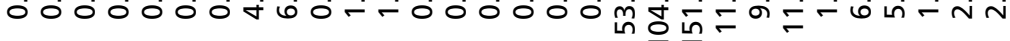

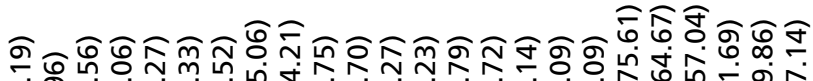

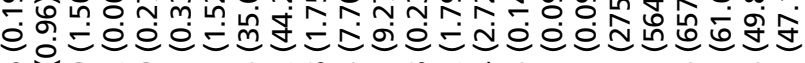

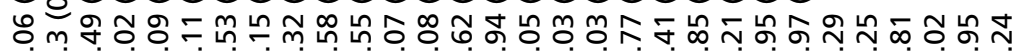

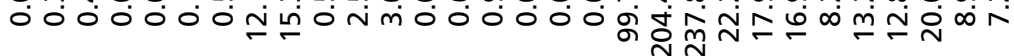

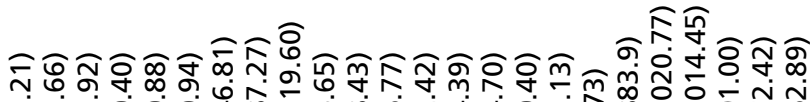

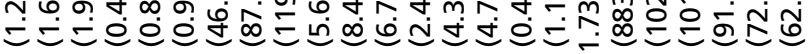

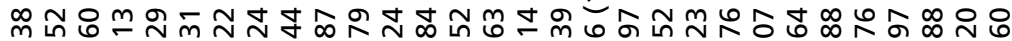
$0000000 \bar{m}=N$ -

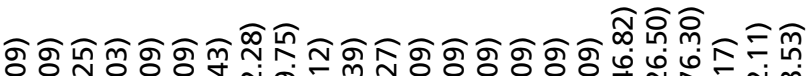

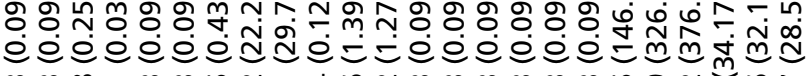

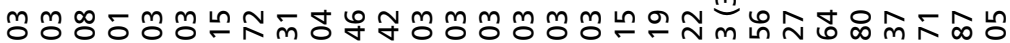

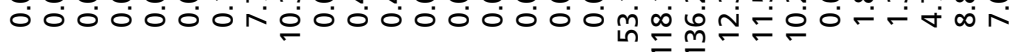

ลิ์

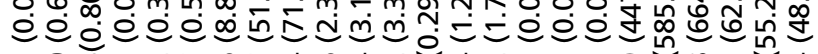

ㄸ.

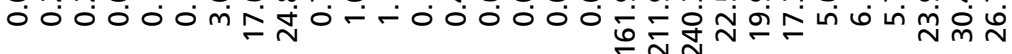

है

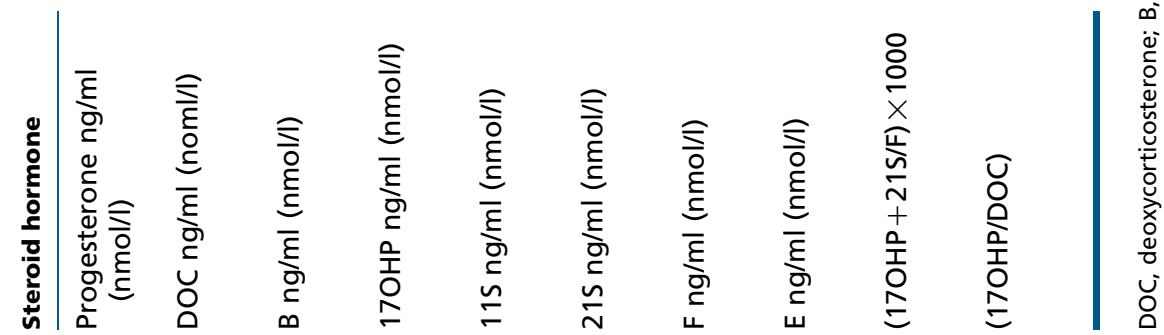




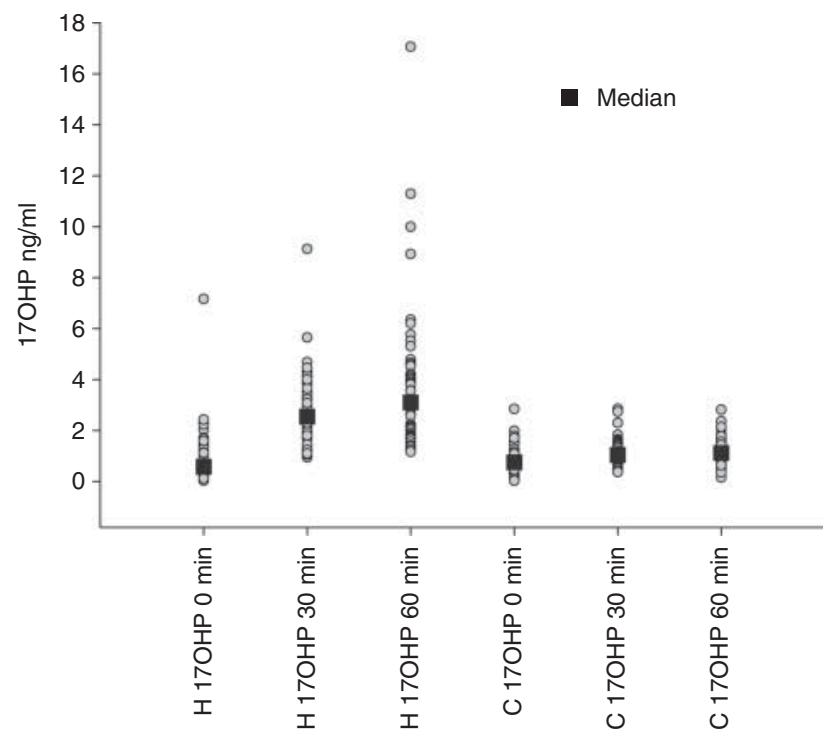

\section{Figure 1}

17-hydroxyprogesterone concentrations in heterozygous carriers of CYP21A2 mutations $(\mathrm{H})$ and healthy controls $(\mathrm{C})$ at baseline, 30 and 60 min following ACTH i.v.

Based on the Kolmogorov-Smirnov test, the assumption of normal distribution of the data was rejected for most of the variables, so the median and the reference values $5-95 \%$ (90\% confidence limits) were calculated using the Harrell-Davis nonparametric quantile estimator (20). The nonparametric Wilcoxon rank sum test was used to evaluate differences between the groups. Adjusted $P$ values were derived from a logistic regression model with age and sex as covariates. Receiver operator characteristics (ROC) were used to define the cut-off value for the ACTH-stimulated ratios $(17 \mathrm{OHP}+21 \mathrm{~S}) / \mathrm{F}, 17 \mathrm{OHP} / \mathrm{DOC}$, and for the delta concentration levels of $17 \mathrm{OHP}$ between heterozygotes and controls. The positive and negative predictive values (PPV and NPV) for 17-hydroxyprogesterone +21 -deoxycortisol/cortisol $\times$ $1000((17 \mathrm{OHP}+21 \mathrm{~S}) / \mathrm{F} \times 1000)$ were calculated for an estimated heterozygote frequency of $1 / 51$ to $1 / 61$ for classic mutations and of $1 / 17$ for non-classic mutations, as calculated by the Hardy-Weinberg principle based on the data published by Pang \& Clark (6).

\section{Results}

\section{Molecular genetics}

Following genetic testing, it was necessary to re-categorize some of the study participants. Four individuals in the group of $210 H D$ patients' relatives carried neither mutations nor deletions and had to be re-categorized to the group of controls. Four of the subjects in the control group were found to be heterozygotes and had to be re-categorized vice versa accordingly.

\section{Hormonal response}

Basal and stimulated plasma concentrations of adrenal hormones are shown in Table 1. As expected, heterozygotes showed significantly higher stimulated concentrations of $17 \mathrm{OHP}$ after 30 and $60 \mathrm{~min}$ (2.55 and $3.07 \mathrm{ng} / \mathrm{ml}$ respectively) compared with the controls $(1.04$ and $1.12 \mathrm{ng} / \mathrm{ml})$ ( $P$ value: $<0.001$ and $<0.001)$. However, the two groups were not distinctly separate since there was a considerable overlap of stimulated $17 \mathrm{OHP}$ concentrations as shown in Fig. 1.

We also found significantly higher concentrations of progesterone in the heterozygous carriers $60 \mathrm{~min}$ after ACTH injection $(0.49 \mathrm{ng} / \mathrm{ml})$ compared with the controls

Table 2 Median and range for the androgens for males, $P$ values and adjusted $P$ values.

\begin{tabular}{|c|c|c|c|c|c|c|c|c|c|}
\hline \multirow{2}{*}{$\begin{array}{l}\text { Steroid } \\
\text { hormone }\end{array}$} & \multirow{2}{*}{$\begin{array}{l}\text { Time } \\
(\min )\end{array}$} & \multicolumn{3}{|c|}{ Controls $n=25$} & \multicolumn{3}{|c|}{ Heterozygous CYP21A2 $n=35$} & \multirow[b]{2}{*}{$\boldsymbol{P}$} & \multirow[b]{2}{*}{$P$ adjust } \\
\hline & & Median & $5 \%$ & $95 \%$ & Median & $5 \%$ & $95 \%$ & & \\
\hline \multirow{3}{*}{$\begin{array}{l}\Delta 4 \mathrm{ng} / \mathrm{dl} \\
\quad(\mathrm{nmol} / \mathrm{l})\end{array}$} & 0 & $135.91(4.75)$ & $49.97(1.75)$ & $279.85(9.78)$ & $134.45(4.70)$ & $34.66(1.21)$ & $217.96(7.62)$ & NS & NS \\
\hline & 30 & $145.57(5.09)$ & $72.59(2.54)$ & $244.4(8.55)$ & $127.64(4.46)$ & $29.07(1.02)$ & 259.9 (9.09) & NS & NS \\
\hline & 60 & 113.87 (3.98) & $52.70(1.84)$ & 248.53 (8.69) & 374.95 (13.11) & $3.49(0.12)$ & $687.75(24.05)$ & NS & NS \\
\hline \multirow{3}{*}{$\begin{array}{l}\text { Testosterone } \\
\text { ng/dl } \\
\text { (nmol/l) }\end{array}$} & 0 & $501.03(17.40)$ & $242.19(8.41)$ & $745.40(25.88)$ & $345.74(12.00)$ & $12.07(0.42)$ & $563.77(19.58)$ & 0.01 & 0.01 \\
\hline & 30 & 507.6 (17.63) & $222.35(7.72)$ & $777.56(27.00)$ & 371.35 (12.89) & $3.75(0.13)$ & $618.14(21.46)$ & 0.01 & 0.01 \\
\hline & 60 & $478.61(16.62)$ & $168.69(5.86)$ & $850.87(29.54)$ & 371.35 (12.89) & $3.75(0.13)$ & $618.14(21.46)$ & 0.01 & 0.01 \\
\hline \multirow{3}{*}{$\begin{array}{r}\text { DHT ng/dl } \\
\text { (nmol/l) }\end{array}$} & 0 & $53.68(1.85)$ & $15.85(0.55)$ & $105.86(3.65)$ & $47.88(1.65)$ & $2.90(0.10)$ & $87.36(3.01)$ & NS & NS \\
\hline & 30 & 55.98 (1.93) & $22.14(0.76)$ & $91.9(3.17)$ & $41.88(1.44)$ & $2.90(0.10)$ & $98.73(3.40)$ & NS & NS \\
\hline & 60 & 48.50 (1.67) & $20.95(0.72)$ & $112.45(3.88)$ & 44.78 (1.54) & $2.90(0.10)$ & $92.80(3.20)$ & NS & NS \\
\hline
\end{tabular}

$\Delta 4$, androstenedione; DHT, dihydrotestosterone. 
Table 3 Median and range for testosterone for males only, adults, $P$ values and adjusted $P$ values.

\begin{tabular}{|c|c|c|c|c|c|c|c|c|c|}
\hline \multirow[b]{2}{*}{ Steroid hormone } & \multirow{2}{*}{$\begin{array}{l}\text { Time } \\
(\min )\end{array}$} & \multicolumn{3}{|c|}{ Controls $n=25$} & \multicolumn{3}{|c|}{ Heterozygous CYP21A2 $n=27$} & \multirow[b]{2}{*}{$\boldsymbol{P}$} & \multirow{2}{*}{$\begin{array}{c}P \\
\text { adjust }\end{array}$} \\
\hline & & Median & $5 \%$ & $95 \%$ & Median & $5 \%$ & $95 \%$ & & \\
\hline \multirow{3}{*}{$\begin{array}{l}\text { Testosterone ng/dl } \\
\text { (only adults) ( } \mathrm{nmol} / \mathrm{l})\end{array}$} & 0 & $500.80(17.39)$ & $249.13(8.65)$ & $765.82(26.59)$ & $388.26(13.48)$ & $202.6(7.03)$ & $753.17(26.15)$ & NS & NS \\
\hline & 30 & $492.91(17.11)$ & $225.36(7.83)$ & $764.95(26.56)$ & 363.41 (12.62) & $190.85(6.63)$ & $591.69(20.54)$ & NS & NS \\
\hline & 60 & $481.75(16.73)$ & $134.06(4.65)$ & 973.93 (33.82) & 378.06 (13.13) & $77.24(2.68)$ & $590.33(20.55)$ & NS & NS \\
\hline
\end{tabular}

$\Delta 4$, androstenedione; DHT, dihydrotestosterone.

$(0.25 \mathrm{ng} / \mathrm{ml})$ ( $P$ value: $<0.001)$. As observed for 17OHP, there was a significant overlap between the groups. Another difference between controls and carriers were the baseline concentrations of corticosterone and cortisol, which were significantly higher in the controls (corticosterone: $3.06 \mathrm{ng} / \mathrm{ml}$, cortisol: $161.99 \mathrm{ng} / \mathrm{ml}$ ) compared with the carriers (corticosterone: $0.53 \mathrm{ng} / \mathrm{ml}$, cortisol: $99.77 \mathrm{ng} / \mathrm{ml}$ ) ( $P$ values: 0.005 and 0.006 respectively). In contrast, there was no significant difference in the stimulated levels of corticosterone and cortisol between the cohorts. For DOC and cortisone, we did not find any significant differences between the groups. For $11 \mathrm{~S}$ we found weakly significant differences for the stimulated concentrations after 30 and $60 \mathrm{~min}$.

Androstenedione $(\Delta 4)$, testosterone and dihydrotestosterone (DHT) differed significantly between the sexes at baseline and after ACTH stimulation (Tables 2, 3, and 4), while mineralocorticoids and glucocorticoids did not vary according to the sex of the subjects (Tables 2, 3, and 4). There were no significant increases of $\Delta 4$, testosterone or DHT in either sex. The differences reported for mineralocorticoids and glucocorticoids between heterozygotes and controls remained significant after the exclusion of prepubertal and pubertal children with only slightly different $P$ values (Table 1). We therefore kept the children in the cohorts for calculations.
In addition to the absolute hormone concentrations, we observed significant differences (=deltas) in the ACTHinduced increases of plasma concentrations between controls and heterozygotes. We found significant differences in delta corticosterone between the groups after 30 min ( $P$ value: $<0.001)$ and after 60 min $(P$ value: $<$ $0.001)$, in delta $17 \mathrm{OHP}$ after $30 \mathrm{~min}(P$ value: $<0.001)$ and $60 \mathrm{~min}(P$ value: $<0.001)$ and in delta cortisol after $30 \mathrm{~min}$ $(P$ value: $<0.001)$ and $60 \mathrm{~min}(P$ value: $<0.001)$. All results were used for a ROC analysis to distinguish between controls and carriers. In the male subjects, we observed a cut-off of $1.28 \%$ for delta $17 \mathrm{OHP}$ after $60 \mathrm{~min}$ with a sensitivity of $80 \%$ and a specificity of $95 \%$. Since this failed in women, we excluded this approach from further calculations. ROC also failed for deltas of all other hormones (data not shown).

We then tested the ratio 17OHP/DOC previously published by Peter et al. (15). Since Peter et al. performed their RIAs following column extraction, these values were anticipated to be fairly comparable to our LC-MS/MS data. We confirmed significant differences for ACTH-stimulated 17OHP/DOC ratios between the two groups at both time points, after 30 and $60 \mathrm{~min}(P$ values: $<0.001,<0.001$ respectively). ROC analysis revealed 0.849 (30 $\mathrm{min})$ and 0.885 (60 min) for the area under the curve (AUC). After $30 \mathrm{~min}$, we revealed a sensitivity of $76 \%$ and a specificity

Table 4 Median and range for the androgens for females, $P$ values and adjusted $P$ values.

\begin{tabular}{|c|c|c|c|c|}
\hline \multirow[b]{2}{*}{ Steroid hormone } & \multirow{2}{*}{$\begin{array}{l}\text { Time } \\
(\min )\end{array}$} & \multicolumn{3}{|c|}{ Controls $n=19$} \\
\hline & & Median & $5 \%$ & $95 \%$ \\
\hline \multirow[t]{3}{*}{$\Delta 4 \mathrm{ng} / \mathrm{dl}(\mathrm{nmol} / \mathrm{l})$} & 0 & $78.42(2.74)$ & $15.48(0.54)$ & $152.36(5.33)$ \\
\hline & 30 & $90.52(3.17)$ & $23.41(0.82)$ & $171.11(5.98)$ \\
\hline & 60 & 114.06 (3.99) & $28.98(1.01)$ & 190.09 (6.65) \\
\hline \multirow{3}{*}{$\begin{array}{l}\text { Testosterone } \mathrm{ng} / \mathrm{dl} \\
\quad(\mathrm{nmol} / \mathrm{l})\end{array}$} & 0 & $30.53(1.06)$ & $7.37(0.26)$ & $290.77(10.10)$ \\
\hline & 30 & $26.81(0.93)$ & $4.88(0.17)$ & $75.52(2.62)$ \\
\hline & 60 & $30.04(1.04)$ & $10.56(0.37)$ & $433.20(15.04)$ \\
\hline \multirow[t]{3}{*}{ DHT ng/dl (nmol/l) } & 0 & $15.28(0.53)$ & $3.56(0.12)$ & 47.62 (1.64) \\
\hline & 30 & $24.16(0.83)$ & $1.19(0.04)$ & 79.74 (2.75) \\
\hline & 60 & $19.47(0.67)$ & $2.90(0.10)$ & $169.63(5.85)$ \\
\hline
\end{tabular}

\begin{tabular}{|c|c|c|c|c|}
\hline \multicolumn{3}{|c|}{ Heterozygous CYP21A2 $n=23$} & \multirow[b]{2}{*}{$\boldsymbol{P}$} & \multirow{2}{*}{$\begin{array}{c}P \\
\text { adjust }\end{array}$} \\
\hline Median & $5 \%$ & $95 \%$ & & \\
\hline $81.17(2.84)$ & $33.44(1.17)$ & $294.21(10.29)$ & NS & NS \\
\hline 116.89 (4.09) & $37.57(1.31)$ & $205.25(7.18)$ & 0.1 & 0.04 \\
\hline $116.40(4.07)$ & $62.62(2.19)$ & $360.33(12.60)$ & NS & NS \\
\hline $17.37(0.60)$ & $2.52(0.09)$ & $97.14(3.37)$ & NS & NS \\
\hline $24.62(0.85)$ & $10.66(0.37)$ & $40.36(1.40)$ & NS & NS \\
\hline $21.25(0.74)$ & $5.14(0.18)$ & $110.34(3.83)$ & NS & NS \\
\hline $19.00(0.66)$ & $2.25(0.08)$ & $35.91(1.24)$ & NS & NS \\
\hline $17.97(0.62)$ & $2.77(0.09)$ & $38.83(1.34)$ & NS & NS \\
\hline $17.89(0.62)$ & $6.02(0.21)$ & $42.17(1.45)$ & NS & NS \\
\hline
\end{tabular}

$\Delta 4$, androstenedione; DHT, dihydrotestosterone. 


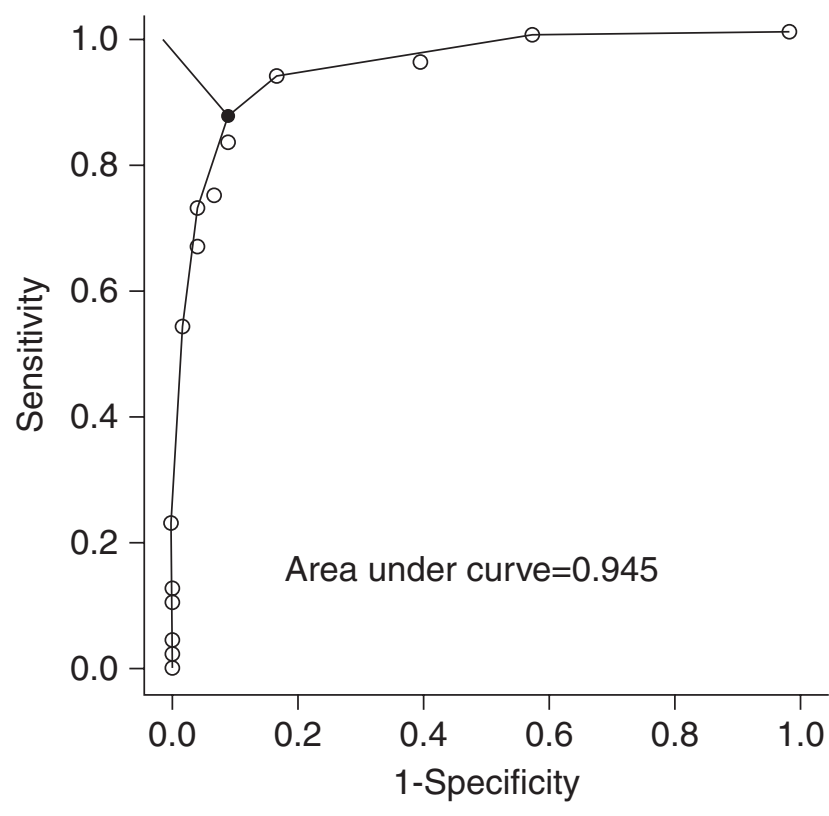

Figure 2

ROC analysis for the $((170 H P+21 S) / F \times 1000)$ equation $30 \mathrm{~min}$ after ACTH injection. The marked black spot indicates the optimal cut-off of 8.4 .

of $56 \%$ for correct diagnosis of heterozygosity. After $60 \mathrm{~min}$, respective values were 70 and $63 \%$.

We observed markedly higher values for AUC (0.934 at $30 \mathrm{~min}$ and 0.924 at $60 \mathrm{~min}$ respectively) when we inserted the ACTH-stimulated concentrations for $17 \mathrm{OHP}$, $21 \mathrm{~S}$ and cortisol into the equation $((17 \mathrm{OHP}+21 \mathrm{~S}) / \mathrm{F} \times$ 1000) (Fig. 2, ROC analysis). This has previously been reported by Janzen et al. (21) in the context of neonatal screening for CAH. A cut-off value of 8.4 (8.0 for adults excluding the prepubertal and pubertal children) for the ACTH-stimulated $((17 \mathrm{OHP}+21 \mathrm{~S}) / \mathrm{F} \times 1000)$ equation after 30 min provides $89 \%$ sensitivity and $89 \%$ specificity. If a specificity of $100 \%$ is defined (no false-positive hormonal prediction of a genetically proven carrier status), the cut-off value for the ACTH-stimulated $((17 \mathrm{OHP}+21 \mathrm{~S}) /$ $\mathrm{F} \times 1000$ ) equation after $30 \mathrm{~min}$ is 14.7 with a sensitivity of $42 \%$. Figure 3 shows the calculated $((17 \mathrm{OHP}+21 \mathrm{~S}) / \mathrm{F} \times 1000)$ ratios for all heterozygous carriers and all controls, together with the optimal cutoff value of 8.4. Of note, each of the re-categorized heterozygous individuals responded to cosyntropin exactly as predicted from the $((17 \mathrm{OHP}+21 \mathrm{~S}) / \mathrm{F} \times 1000)$ equation (i.e., all heterozygotes $>8.4$ ), as did all the re-categorized homozygous controls (i.e., all homozygotes controls <8.4). Based on the data for sensitivity, specificity and heterozygote frequency in the population (Hardy-Weinberg principle) (22), we revealed a PPV of $12 \%$ and a NPV of $99.8 \%$ for classical mutations and a PPV of $33 \%$ and a NPV of $99.2 \%$ for non-classical mutations.

\section{Discussion}

Compared with all other tested parameters, the result of the equation $((17 \mathrm{OHP}+21 \mathrm{~S}) / \mathrm{F} \times 1000) 30 \mathrm{~min}$ after $\mathrm{ACTH}$ stimulation proved to be the best for specific and sensitive identification of heterozygotes in our study, with a statistically optimal cut-off value of 8.4 . We could not reproduce the high $100 \%$ specificity and sensitivity of the $17 \mathrm{OHP} / \mathrm{DOC}$ ratio that was found by Peter et al. (15) based on RIA following column extraction verified by human leukocyte antigen (HLA) haplotyping. In fact, in our study, the $17 \mathrm{OHP} / \mathrm{DOC}$ ratio was markedly inferior to the $(17 \mathrm{OHP}+21 \mathrm{~S}) / \mathrm{F}$ equation using the new LC-MS/MS data.

Janzen et al. (21) previously applied the (17OHP+ 21S)/F ratio in newborn screening for classical $210 H D$. The much higher cut-off value of 0.53 (530 when using $((17 \mathrm{OHP}+21 \mathrm{~S}) / \mathrm{F} \times 1000))$, combined with much higher sensitivity of $100 \%$ and specificity of $99 \%$, is not in contradiction to our present study. Janzen et al. (21) analyzed classical CAH patients with extensive changes in their steroid hormones compared with our cohort, in which heterozygotes are only expected to show very subtle

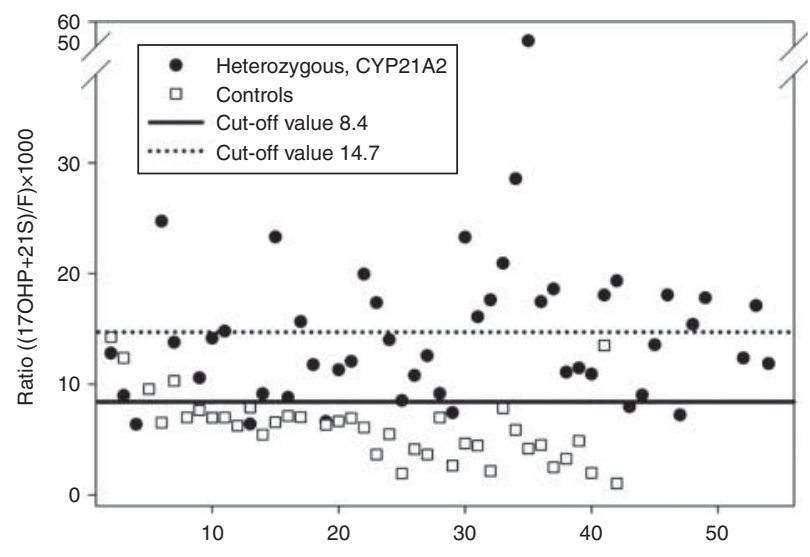

\section{Figure 3}

Ratio of 17-hydroxyprogesterone +21 -deoxycortisol/cortisol $\times$ $1000((17 \mathrm{OHP}+21 \mathrm{~S} / \mathrm{F}) \times 1000)$ for heterozygous carriers of CYP21A2 mutations and healthy controls. Solid line: the optimal cut-off value (8.4); dotted line: the $100 \%$ specificity cut-off value (14.7). 
deviations in the steroid metabolome, with hormone concentrations still within the normal ranges. The Janzen et al. (21) study thus supports our present strategy of including $21 \mathrm{~S}$ and cortisol rather than 17OHP/DOC for sensitive and specific detection of the carrier status. We also did not find the significant correlation between $17 \mathrm{OHP}$ and 21S published by Costa-Barbosa et al. (23). This is possibly due to the fact that we only studied asymptomatic heterozygous carriers instead of non-classic $\mathrm{CAH}$ patients.

Despite the remarkably high values for specificity and sensitivity of the $((17 \mathrm{OHP}+21 \mathrm{~S}) / \mathrm{F} \times 1000)$ equation using the optimal cut-off of 8.4, and considering the only marginal metabolic changes anticipated in heterozygotes, both parameters still did not reach $100 \%$. This approach, therefore, is not suitable as a general replacement for genetic testing. Interestingly, though, a $((17 \mathrm{OHP}+21 \mathrm{~S}) /$ $\mathrm{F} \times 1000)$ ratio exceeding 14.7 has a specificity of $100 \%$ for correct prediction of heterozygosity. However, in this case sensitivity at the cohort level is limited (42\%) so this cut-off would miss a significant number of true heterozygotes. The high NPV of the $((17 \mathrm{OHP}+21 \mathrm{~S}) / \mathrm{F} \times$ 1000) equation below 8.4 is also clinically relevant because it excludes heterozygosity in $99.8 \%$ of tested cases. We conclude that LC-MS/MS-based determination of only the three hormones 17OHP, $21 \mathrm{~S}$ and cortisol following ACTH stimulation is a straightforward, fast and comparably simple test that can be of significant assistance to the clinician in the suspicion, the identification or exclusion of heterozygosity of CYP21A2 gene mutations. On the one hand, this can be valuable under conditions in which hormone determinations are possible but access to genetic testing is limited due to financial restrictions of health care systems or health insurances. Since heterozygosity of CYP21A2 gene mutations has to be considered in the differential diagnosis of hyperandrogenism $(7,8,9,10)$ and since the ACTH test is often performed in these clinical situations $(24,7)$, calculation of $((17 \mathrm{OHP}+$ $21 S) / F \times 1000$ ) provides important additional information for test interpretation and diagnostic workup.

\section{Supplementary data}

This is linked to the online version of the paper at http://dx.doi.org/10.1530/ EJE-14-1084.

\section{Declaration of interest}

The authors declare that there is no conflict of interest that could be perceived as prejudicing the impartiality of the research reported.
Funding

The study was funded by the HaFo grant of the Medical Faculty of the Christian-Albrechts-University of Kiel, Germany.

\section{Acknowledgements}

The authors wish to thank Tanja Stampe, Brigitte Karvelies, Gisela Hohmann, Susanne Olin, Sabine Stein and Silke Struve for excellent technical assistance.

\section{References}

1 Speiser PW, Azziz R, Baskin LS, Ghizzoni L, Hensle TW, Merke DP, Meyer-Bahlburg HF, Miller WL, Montori VM, Oberfield SE et al. Congenital adrenal hyperplasia due to steroid 21-hydroxylase deficiency: an Endocrine Society clinical practice guideline. Journal of Clinical Endocrinology and Metabolism 201095 4133-4160. (doi:10.1210/ jc.2009-2631)

2 Speiser PW, Dupont B, Rubinstein P, Piazza A, Kastelan A \& New MI. High frequency of nonclassical steroid 21-hydroxylase deficiency. American Journal of Human Genetics 198537 650-667.

3 Lacey JM, Minutti CZ, Magera MJ, Tauscher AL, Casetta B, McCann M, Lymp J, Hahn SH, Rinaldo P \& Matern D. Improved specificity of newborn screening for congenital adrenal hyperplasia by second-tier steroid profiling using tandem mass spectrometry. Clinical Chemistry 200450 621-625. (doi:10.1373/clinchem.2003.027193)

4 Speiser PW \& White PC. Congenital adrenal hyperplasia. New England Journal of Medicine 2003349 776-788. (doi:10.1056/NEJMra021561)

5 Krone N \& Arlt W. Genetics of congenital adrenal hyperplasia. Best Practice \& Research. Clinical Endocrinology \& Metabolism 200923 181-192. (doi:10.1016/j.beem.2008.10.014)

6 Pang S \& Clark A. Newborn screening, prenatal diagnosis, and prenatal treatment of congenital adrenal hyperplasia due to 21-hydroxylase deficiency. Trends in Endocrinology and Metabolism 19901 300-307. (doi:10.1016/1043-2760(90)90068-E)

7 Escobar-Morreale HF, San Millan JL, Smith RR, Sancho J \& Witchel SF. The presence of the 21-hydroxylase deficiency carrier status in hirsute women: phenotype-genotype correlations. Fertility and Sterility 199972 629-638. (doi:10.1016/S0015-0282(99)00317-9)

8 Admoni O, Israel S, Lavi I, Gur M \& Tenenbaum-Rakover Y. Hyperandrogenism in carriers of CYP21 mutations: the role of genotype. Clinical Endocrinology 200664 645-651. (doi:10.1111/ j.1365-2265.2006.02521.x)

9 Paris F, Tardy V, Chalancon A, Picot MC, Morel Y \& Sultan C. Premature pubarche in Mediterranean girls: high prevalence of heterozygous CYP21 mutation carriers. Gynecological Endocrinology 201026 319-324. (doi:10.3109/09513590903511505)

10 Binay C, Simsek E, Cilingir O, Yuksel Z, Kutlay O \& Artan S. Prevalence of nonclassic congenital adrenal hyperplasia in Turkish children presenting with premature pubarche, hirsutism, or oligomenorrhoea. International Journal of Endocrinology 20142014 768506. (doi:10.1155/ 2014/768506)

11 Krensky AM, Bongiovanni AM, Marino J, Parks J \& Tenore A Identification of heterozygote carriers of congenital adrenal hyperplasia by radioimmunoassay of serum 17-OH progesterone. Journal of Pediatrics 197790 930-933. (doi:10.1016/S0022-3476(77) 80561-1)

12 Gourmelen M, Gueux B, Pham Huu Trung MT, Fiet J, Raux-Demay MC $\&$ Girard F. Detection of heterozygous carriers for 21-hydroxylase deficiency by plasma 21-deoxycortisol measurement. Acta Endocrinologica 1987116 507-512. 
13 Witchel SF \& Lee PA. Identification of heterozygotic carriers of 21-hydroxylase deficiency: sensitivity of ACTH stimulation tests. American Journal of Medical Genetics 199876 337-342. (doi:10.1002/ (SICI) 1096-8628(19980401)76:4<337::AID-AJMG9>3.0.CO;2-M)

14 Glintborg D, Hermann AP, Brusgaard K, Hangaard J, Hagen C \& Andersen M. Significantly higher adrenocorticotropin-stimulated cortisol and 17-hydroxyprogesterone levels in 337 consecutive, premenopausal, caucasian, hirsute patients compared with healthy controls. Journal of Clinical Endocrinology and Metabolism 200590 1347-1353. (doi:10.1210/jc.2004-1214)

15 Peter M, Sippell WG, Lorenzen F, Willig RP, Westphal E \& Grosse-Wilde H. Improved test to identify heterozygotes for congenital adrenal hyperplasia without index case examination. Lancet 1990335 1296-1299. (doi:10.1016/0140-6736(90)91185-D)

16 Krone N, Braun A, Weinert S, Peter M, Roscher AA, Partsch CJ \& Sippell WG. Multiplex minisequencing of the 21-hydroxylase gene as a rapid strategy to confirm congenital adrenal hyperplasia. Clinical Chemistry 200248 818-825.

17 Krone N, Roscher AA, Schwarz HP \& Braun A. Comprehensive analytical strategy for mutation screening in 21-hydroxylase deficiency. Clinical Chemistry $1998 \mathbf{4 4}$ 2075-2082.

18 Kulle AE, Riepe FG, Melchior D, Hiort O \& Holterhus PM. A novel ultrapressure liquid chromatography tandem mass spectrometry method for the simultaneous determination of androstenedione, testosterone, and dihydrotestosterone in pediatric blood samples: age- and sex-specific reference data. Journal of Clinical Endocrinology and Metabolism 201095 2399-2409. (doi:10.1210/jc.2009-1670)
19 Kulle AE, Welzel M, Holterhus PM \& Riepe FG. Implementation of a liquid chromatography tandem mass spectrometry assay for eight adrenal C-21 steroids and pediatric reference data. Hormone Research in Poediatrics 201379 22-31.

20 Harrell F \& Davis CE. A new distribution-free quantile estimator. Biometrika 198269 636-640. (doi:10.1093/biomet/69.3.635)

21 Janzen N, Peter M, Sander S, Steuerwald U, Terhardt M, Holtkamp U \& Sander J. Newborn screening for congenital adrenal hyperplasia: additional steroid profile using liquid chromatography-tandem mass spectrometry. Journal of Clinical Endocrinology and Metabolism 200792 2581-2589. (doi:10.1210/jc.2006-2890)

22 Fitness J, Dixit N, Webster D, Torresani T, Pergolizzi R, Speiser PW \& Day DJ. Genotyping of CYP21, linked chromosome $6 \mathrm{p}$ markers, and a sex-specific gene in neonatal screening for congenital adrenal hyperplasia. Journal of Clinical Endocrinology and Metabolism 199984 960-966.

23 Costa-Barbosa FA, Tonetto-Fernandes VF, Carvalho VM, Nakamura OH, Moura V, Bachega TA, Vieira JG \& Kater CE. Superior discriminating value of ACTH-stimulated serum 21-deoxycortisol in identifying heterozygote carriers for 21-hydroxylase deficiency. Clinical Endocrinology 201073 700-706. (doi:10.1111/j.1365-2265.2010.03871.x)

24 Azziz R, Hincapie LA, Knochenhauer ES, Dewailly D, Fox L \& Boots LR. Screening for 21-hydroxylase-deficient nonclassic adrenal hyperplasia among hyperandrogenic women: a prospective study. Fertility and Sterility 199972 915-925. (doi:10.1016/S00150282(99)00383-0)

Received 8 December 2014

Revised version received 9 June 2015

Accepted 21 July 2015 